\title{
LAS CODIFICACIONES CANÓNICAS LATINA Y ORIENTAL: TREINTA AÑOS ENTRE DIVERSIDAD Y CONCORDIA
}

\author{
LATIN AND EASTERN CANONICAL CODIFICATIONS: THIRTY \\ YEARS BETWEEN DIVERSITY AND HARMONY
}

\author{
MIRIAN CORTÉS DIÉGUEZ \\ Universidad Pontificia de Salamanca
}

\section{RESUMEN}

El Concilio Vaticano II destacó la riqueza eclesial de las venerables tradiciones del oriente cristiano, declaró el derecho de las Iglesias orientales a regirse por un derecho propio y les encomendó una misión trascendental. Después de un largo período de codificación, se promulgó el Código de Cánones de las Iglesias Orientales, que ha cumplido en 2021 el trigésimo aniversario de su vigencia. En este trabajo se estudian principalmente: el proceso codificador de las leyes orientales y algunos de los temas clave que fueron debatidos; la relación del nuevo Código oriental con el Código de Derecho Canónico; las razones de la reforma realizada por el Papa Francisco para armonizar ambas legislaciones; la diferenciación de los términos "rito" e "Iglesia sui iuris", así como los elementos materiales y formales de esta última.

Palabras clave: Armonización legislativa, Código de Cánones de las Iglesias Orientales, Código de Derecho Canónico, Iglesia sui iuris, Rito. 


\section{ABSTRACT}

The Second Vatican Council emphasized the ecclesial richness of the venerable traditions of the Christian East, declared the right of the Eastern Churches to govern themselves by their own law and entrusted them with a transcendental mission. After a long period of codification, the Code of Canons of the Eastern Churches was promulgated, which celebrates in 2021 its thirtieth anniversary since it came into force. This work mainly studies: the codifying process of the Eastern laws and some of the key issues that were discussed; the relationship of the new Eastern Code with the Code of Canon Law; the reasons for the reform carried out by Pope Francis to harmonize both legislations; the differentiation of the terms "rite" and "sui iuris Church", as well as the material and formal elements of the latter.

Keywords: Code of Canons of the Eastern Churches, Code of Canon Law, Legislative harmonization, Rite, Sui iuris Church.

\section{INTRODUCCIÓN}

Mediante la Constitución Apostólica Sacri Canones, de 18 de octubre de 1990, Juan Pablo II promulgó el Código de Cánones de las Iglesias Orientales, que entraría en vigor el 1 de octubre de 1991. Se han cumplido pues, treinta años de vigencia de este novedoso instrumento legislativo, largamente deseado y promovido por los Pontífices desde el s. XIX, que dota de un cuerpo de leyes único y común a las Iglesias católicas que tienen su origen en las cinco antiguas tradiciones orientales: alejandrina, antioquena, armenia, caldea y constantinopolitana. Si bien en el plano material estas Iglesias ya contaban con un conjunto de leyes específicas, aprobadas por la Sede Apostólica, formalmente nunca habían tenido un Código propio, al estilo de los latinos de 1917 y el vigente de 1983.

El propio legislador manifestó que el Código de Cánones de las Iglesias Orientales (CCEO) venía a completar finalmente el ordenamiento canónico de la Iglesia universal, junto al precedente Código de Derecho Canónico para la Iglesia latina (CIC) y la Constitución Apostólica Pastor Bonus sobre la Curia romana, de $1988^{1}$. Este conjunto legislativo forma el nuevo y único Corpus iuris

1 Se citarán ambos Códigos según sus siglas en latín: Codex Iuris Canonici (CIC) y Codex Canonum Ecclesiarium Orientalium (CCEO). Las ediciones referidas son las de la Biblioteca de Autores Cristianos de la Conferencia Episcopal Española. $9^{\mathrm{a}}$ ed. (Madrid: 2020); y $3^{\mathrm{a}}$ ed. (Madrid: 2021), respectivamente. 
canonici de la Iglesia ${ }^{2}$, y sus normas deben entenderse como una derivación jurídica del magisterio del Concilio Vaticano II y como contribución al objetivo del mismo de renovar la vida cristiana. No es de extrañar por tanto, que Juan Pablo II pidiese encarecidamente, al aprobar el nuevo CCEO, que se promoviese su estudio entre los canonistas, con el fin de que pudieran tener una verdadera visión de conjunto del derecho de la Iglesia ${ }^{3}$. A nivel académico, tal estudio fue prescrito por el Decreto Novo Codice, que reformó los estudios de derecho canónico en 2002, y refrendado por la Constitución Apostólica Veritatis gaudium sobre las Universidades y Facultades Eclesiásticas, de 8 de diciembre de 2017.

Emprendemos este trabajo animados por la necesidad de contribuir al conocimiento de las Iglesias orientales y su derecho, cuyo estudio no abunda entre los canonistas, e igualmente interpelados por la especial consideración que tanto el Concilio Vaticano II como los Papas vienen dispensando a estas Iglesias. Junto a ello, debemos tener en cuenta la creciente realidad de la presencia en territorios latinos de fieles pertenecientes a alguna de las más de veinte Iglesias orientales católicas sui iuris, que requieren una atención específica por parte de los pastores de la Iglesia latina.

El oriente cristiano, por ser el marco originario de la Iglesia primitiva, conserva las más genuinas tradiciones de los padres de la Iglesia, que arrancan de los mismos apóstoles. La Iglesia considera que tal venerable y antigua tradición, desarrollada en diversos modos especiales de comprender y vivir la fe, constituye parte integrante del patrimonio de la Iglesia de Cristo y, por tanto, de la Iglesia universal. De ahí la necesidad de preservar íntegro el depósito de la fe que custodian estas Iglesias, así como de respetar su modo peculiar de organización, en orden a lo cual es importante contar con los instrumentos jurídicos adecuados. En los dos Concilios ecuménicos contemporáneos, el Vaticano I y el Vaticano II, se trató el asunto de la revisión del derecho canónico oriental, y en ambos se reconoció de modo claro la necesidad de elaborar un Código específico que constituyera la disciplina común a todas las Iglesias orientales.

El texto de todos los documentos normativos o doctrinales del legislador universal (Concilio Vaticano II y Pontífices), salvo que se indique otra cita, está tomado de la traducción española publicada en la web oficial del Vaticano https://www.vatican.va/content/vatican/es.html. En el listado de fuentes, al final, se incluyen los respectivos enlaces.

2 Cf. Juan Pablo II, "Discorso in occasione della presentazione del Codice dei Canoni delle Chiese Orientali" (25 de octubre de 1990).

3 Puede verse un estudio sobre el interés para los canonistas latinos del derecho oriental, así como sobre canonistas dedicados a la enseñanza y el estudio de este último derecho, con abundante bibliografía, en Pablo Gefaell, "El derecho oriental desde la promulgación del CIC y del CCEO”, Ius canonicum 97 (2009): 37-65. 
Juan Pablo II, legislador tanto del CIC de 1983 como del CCEO, dejó constancia en su magisterio de la necesidad de que la Iglesia respirase plenamente con sus "dos pulmones" para la efectividad de su misión ${ }^{4}$. Resulta evidente que ambos pulmones, que representan simbólicamente al occidente y oriente católicos, han de trabajar en armonía y sintonía. Como contribución a tal fin, el Papa Francisco promulgó el 31 de mayo de 2016 la Carta Apostólica en forma de motu proprio De concordia inter codices, con la que modifica algunas normas del CIC, a fin de armonizar determinadas disposiciones y expresiones con el CCEO.

En una primera parte del estudio, tras una breve referencia a la distinción entre Iglesia latina y oriental, nos referiremos al proceso que, a lo largo de los pontificados de finales del s. XIX y del XX, llevó a la promulgación de un Código específico para las Iglesias católicas orientales. Nos detendremos especialmente en la presencia del oriente católico en el Concilio Vaticano II y en los principales temas de debate que se plantearon durante las etapas de la codificación. En una segunda parte nos centraremos en la reciente reforma operada por el citado motu propio, especialmente en lo relativo a los motivos de la misma y a los aspectos conceptuales. Finalmente abordaremos el estudio de las notas distintivas de la noción de Iglesia sui iuris, con la cual se designa en el CCEO, de modo acorde a su naturaleza eclesial y jurídica propia, a las Iglesias orientales católicas.

\section{IGLESIA LATINA E IGLESIAS ORIENTALES}

\section{APUNTE HISTÓRICO}

La Iglesia católica, nacida en tiempos de la Roma imperial, acabó tomando para su propia organización la distinción convencional de los territorios del Imperio en orientales y occidentales 5 .

La denominada Iglesia oriental de los primeros siglos del cristianismo, de fundación apostólica, estaba constituida por los patriarcados de Constantinopla, Alejandría, Antioquía y Jerusalén, mientras que la parte occidental ordenaba su

4 La equiparación del Oriente y el Occidente católicos con los dos pulmones de la Iglesia es una expresión de Juan Pablo II. Cf. v.gr. "Encíclica Redemptoris mater" (25 de marzo de 1987), 34; "Carta Encíclica Ut unum sint" (25 de mayo de 1995), 54; "Exhortación apostólica post sinodal Ecclesia in America" (22 de enero de 1999), 17.

5 Con la Paz constantiniana (a. 315) y el primer Concilio ecuménico (Nicea, 325) la Iglesia se acomodará al Imperio en cuanto a su organización, y el Imperio se consolidará gracias a la unidad de fe. Cf. Carlos De Francisco Vega, Las Iglesias orientales católicas, (Madrid: San Pablo, 1997), 23. 
vida y acción bajo el patriarcado de Roma, que ostentaba la presidencia al ser el centro del catolicismo.

Pero más allá de la división puramente convencional, e incluso, más que la efectiva distancia geográfica respecto de Roma, lo realmente relevante eran las diferencias culturales, modo de vida y mentalidad de los habitantes de una y otra zona del Imperio, que a su vez llevaron a diversas formas de religiosidad. Sin perder, por tanto, la sustancia de la fe, los cristianos que ocupaban los territorios del viejo Imperio romano desarrollaron una teología y espiritualidad propias, una jerarquía y régimen disciplinar específico, así como un conjunto de variantes litúrgicas. Por otra parte, en Roma el latín sustituyó al griego y se convirtió en la lengua oficial, por lo que la Iglesia bajo el patriarcado romano comenzó a denominarse latina. En oriente en cambio, bajo la influencia cultural bizantina, los cristianos mantuvieron sus lenguas propias en la liturgia, mostrando, desde sus orígenes, una capacidad especial para asumir los rasgos característicos de cada cultura y comunidad particular ${ }^{6}$.

Esta diversidad oriental fue sancionada por los santos padres, considerados portadores de la Tradición de la Iglesia, y sucesivamente por los concilios ecuménicos. La Iglesia católica entiende que tal variedad en nada perjudica la unidad eclesial, sino que, por el contrario, se hace necesaria para explicitarla en toda su riqueza y ponerla al servicio de su misión.

Se estima que actualmente las Iglesias orientales católicas agrupan a unos quince millones de fieles, que representan apenas un dos por ciento del total estimado de católicos y que se encuentran, además, dispersos por el mundo, sobre todo los que viven en territorios de Estados Unidos, América Latina o Europa. Su número es también ínfimo si lo comparamos con el resto del oriente cristiano, especialmente con los alrededor de doscientos treinta millones de ortodoxos, pero la Iglesia católica confía a ellos uno de sus más altos anhelos: la unidad de todos los cristianos, y espera que, a modo de levadura, los católicos orientales sean el fermento que un día permita volver a la unión de la Iglesia.

\section{MisIÓN PECULIAR DE LAS IGLESIAS CATÓLICAS ORIENTALES}

Para comprender el cuidado que singularmente los Romanos Pontífices dispensan a las Iglesias católicas orientales y a sus fieles, basta ahora recordar que

6 Juan Pablo II, “Carta Apostólica Orientale Lumen, al episcopado, al clero y a los fieles con ocasión del centenario de la Orientalium dignitas del Papa León XIII" (2 de mayo de 1995), 5. En adelante se citará en forma breve como Juan Pablo II, OL. 
el Concilio Vaticano II les confió, expresamente, la tarea de "fomentar la unión de todos los cristianos, sobre todo de los orientales"

La unidad, junto a la libertad y la paz, fueron los temas centrales del pontificado de Juan XXIII. El motu proprio Superno Dei Nutu (5 de junio de 1960), con el que abrió la fase para la inmediata preparación del Concilio, declaraba:

"con la solemne asamblea (...) respecto de los que, gloriándose del nombre cristiano viven con todo separados de esta Sede Apostólica, brilla de nuevo la esperanza de que, oyendo las voces del divino Pastor, vengan a la única Iglesia de Cristo"(primer párrafo).

Igualmente, en la Constitución Apostólica Humanae salutis, mediante la que convocó el Concilio Vaticano II el 25 de diciembre de 1961, dejó constancia de que uno de los objetivos conciliares era contribuir a recomponer la unidad visible de todos los cristianos:

"la Iglesia anhela fortalecer su fe y mirarse una vez más en el espectáculo maravilloso de su unidad" (n. 7).

"En un tiempo, además, de generosos y crecientes esfuerzos que en no pocas partes se hacen con el fin de rehacer aquella unidad visible de todos los cristianos que responda a los deseos del Redentor divino, es muy natural que el próximo Concilio aclare los principios doctrinales y dé los ejemplos de mutua caridad, que harán aún más vivo en los hermanos separados el deseo del presagiado retorno a la unidad y le allanarán el camino" (n. 8).

La consecución de este fin encontraba y sigue encontrando su principal esperanza en el hecho de que todas las Iglesias orientales, estén o no en comunión con la Iglesia católica, comparten un mismo patrimonio espiritual, litúrgico, teológico y disciplinar que tiene su origen en los 'sagrados cánones' de los primeros siglos de la Iglesia ${ }^{8}$. Estos cánones, que son considerados prescripciones que proceden de los propios apóstoles, fueron recogidos por los primeros sínodos y concilios y transmitidos por los santos padres. El séptimo Concilio ecuménico, que tuvo lugar en la sede de Nicea en el año 787, los consideró como un único Corpus legislativo para todas las Iglesias orientales.

Por tanto, son estas mismas prescripciones sagradas de los primeros siglos de la Iglesia las que, a un tiempo, inspiran la actual codificación oriental

7 Concilio Vaticano II, "Decreto Orientalium Ecclesiarum sobre las Iglesias orientales católicas" (21 de noviembre de 1964), 24. En adelante se citará en forma breve como Concilio Vaticano II, OE.

8 Concilio Vaticano II, OE, 1. 
(promulgada mediante una Constitución Apostólica que lleva precisamente por título Sacri canones) y fundamentan en gran medida la disciplina de las Iglesias ortodoxas $^{9}$. El Vaticano II mostró una honda estima hacia este patrimonio oriental común, que es fruto de la tradición canónica de la Iglesia indivisa del primer milenio, y por ello encomendó a los católicos orientales esta especial misión ecuménica respecto a las "Iglesias hermanas"10, con las que comparten el privilegio de ser portadores de las venerables y antiguas tradiciones orientales, que constituyen la más genuina tradición eclesial.

Congruentemente con esta intención, cuando Pablo VI inauguró los trabajos de la Comisión Pontificia que habría de redactar el Código oriental, indicó a sus miembros que debía configurarse de modo que se adaptase a tal peculiar función de favorecer la unidad de todos los cristianos. Se aseguró, además, que participasen como observadores algunos invitados de las Iglesias orientales separadas de Roma. No es de extrañar, por tanto, que varios de los principios directivos para la redacción del nuevo Código, que fueron aprobados casi por unanimidad por la Comisión, se referían a esta cuestión. Algunos de los principales están recogidos en el Prefacio del CCEO, entre ellos:

"El Código ha de reflejar la disciplina que se contiene en los sagrados cánones $\mathrm{y}$ en las costumbres comunes a todas las Iglesias orientales".

"El Código debe ser completamente conveniente para la peculiar misión, confiada por el Concilio Vaticano II a las Iglesias orientales católicas, de favorecer la unidad de todos los cristianos, especialmente de los orientales".

De acuerdo con el mandato pontificio, el CCEO dedicará todo su título XVIII al ecumenismo (cc. 902 a 908). En él se destaca que las Iglesias católicas orientales tienen el "deber especial" de fomentar la unidad entre las Iglesias orientales y acentúa el papel de los obispos eparquiales en esta tarea.

Después del CCEO, a la luz del nuevo marco normativo creado por este, se aprobó el Directorio para la aplicación de principios y normas sobre el Ecumenismo ${ }^{11}$, cuya elaboración se había pedido durante el Concilio, con la finalidad de orientar, coordinar y desarrollar el esfuerzo ecuménico de toda la Iglesia.

9 Concilio Vaticano II, OE, 1.

10 Sobre el concepto de "Iglesias hermanas" cf. Juan Pablo II, Ut unum sint, cit., 55-56. Sobre el patrimonio espiritual común entre "Iglesias hermanas" cf. Pablo Blanco, "Las Iglesias orientales católicas y ortodoxas en las enseñanzas del Vaticano II", Scripta Theologica 46 (2014): 359-364.

11 Pontificio Consejo para la Promoción de la Unidad de los Cristianos, "Directorio para la Aplicación de Principios y Normas sobre el ecumenismo" (25 de mazo de 1993). Puede consultarse en

http://www.christianunity.va/content/unitacristiani/it/documenti/direttorio-per-lapplicazione-deiprincipi-e-delle-norme-sullecum.html 
Posteriormente, Juan Pablo II emanó dos documentos fundamentales para este mismo fin: la Carta Encíclica Ut unum sint, sobre el empeño ecuménico, y la Carta Apostólica Orientale lumen, en la que manifiesta de nuevo que las Iglesias de Oriente son quienes vienen a su pensamiento, al igual que sucedió a sus predecesores, como principales agentes para la unidad de la Iglesia de $\mathrm{Cristo}^{12}$, que es una y debe ser una.

\section{LAS IGLESIAS CATÓLICAS ORIENTALES EN EL CONCILIO VATICANO II ${ }^{13}$}

La representación de las Iglesias Orientales católicas en la etapa preparatoria del Concilio Vaticano II estuvo garantizada con la presencia de los cinco Patriarcas en la Comisión Central, presidida por el propio Pontífice, lo cual indica que se les quiso atribuir un puesto relevante.

Además, se constituyó una Comisión específica para las Iglesias Orientales, de entre las doce creadas para elaborar la temática que sería objeto de examen en el aula conciliar. Dicha Comisión tenía, lógicamente, la composición más variada de todas, tanto por los países, razas, lenguas y ritos que representaban. Igualmente, su competencia se extendió a un gran número de asuntos propios de las Iglesias orientales, mientras que el estudio de problemas diversos atinentes a la Iglesia latina se repartían entre varias de las Comisiones preparatorias.

Junto al Cardenal presidente y el secretario formaban parte de ella veintiséis miembros y treinta consultores, que representaban a veinticuatro países y dieciséis familias religiosas. Se buscó un equilibrio entre personas de gobierno y de estudio, y entre representantes de los diversos ritos y pueblos ${ }^{14}$.

La Comisión Oriental dividió su trabajo en seis secciones: teológica, jurídica, histórica, litúrgica, unionista y pastoral, y presentó al examen de la Comisión Central once esquemas de Decretos, sobre los siguientes temas: sacramentos, ritos y preceptos de la Iglesia oriental, patriarcas, relaciones con los

12 Juan Pablo II, OL 1 y 3.

13 Para la redacción de este epígrafe hemos consultado la Documentación original preparada por la Oficina de Prensa del Concilio Ecuménico Vaticano II que consta en el Archivo de la Biblioteca de la UPSA, en concreto la parte relativa a la "Composición, actividades y características de las Comisiones y Secretariados preparatorios del Concilio Vaticano II".

14 Estaban representados el rito alejandrino, con sus derivaciones de coptos y etíopes; el rito antioqueno, con los siros, maronitas, y malankareses; el rito bizantino, con los ucranianos, rutenos, griegos, italo-albaneses, melquitas, rumenos, rusos, búlgaros y yugoslavos; el rito caldeo, con caldeos y malabareses; y el rito armeno. 
acatólicos en las cuestiones sacras, uso de la lengua vulgar, facultades de los obispos, catecismo, celebración de la pascua, oficio divino y unidad de la Iglesia.

Un año después del inicio de las sesiones conciliares, concretamente el 14 de octubre de 1963, durante la celebración de la XLVII Congregación general, los cinco Patriarcas (Esteban Sidarous, copto; Máximo IV Saigh, melquita de Antioquía; Pedro Pablo Meuchi, maronita de Antioquía; Pablo II Cheikho, caldeo de Babilonia; e Ignacio Pedro XVI Batanian, armeno) comenzaron a ocupar un lugar más distinguido en el aula, pasando de tener un puesto de honor después de los Cardenales a situarse enfrente de los mismos, al lado de la estatua de San Pedro. Junto a ellos se situó Alberto Gori, patriarca latino de Jerusalén. El sexto Patriarca oriental presente en el Concilio fue el Cardenal Tappouni, que ocupó un puesto en la mesa presidencial del mismo ${ }^{15}$.

El asunto del lugar, que no se trataba de una cuestión menor, ni menos de vanidad o presunción, fue una decisión tomada por el Santo Padre por fidelidad histórica, pues si bien el título de Patriarca en la Iglesia latina es meramente honorífico, el Patriarcado oriental es el modo tradicional de gobierno en las Iglesias orientales, y por tanto, el Patriarca ejerce una amplia potestad de jurisdicción ${ }^{16}$.

De acuerdo con el vocabulario manejado en el Concilio:

"Se llaman Patriarcas en la Iglesia Oriental a algunos Obispos de diócesis muy antiguas, entre las cuales hay varias que se remontan a los tiempos apostólicos. Se les reconoce, por la tradición y en el Código, una autoridad superior a la de los Obispos ordinarios" -si bien- "la particular potestad de jurisdicción atribuida a ellos es, en su origen, únicamente de institución eclesiástica y, por consiguiente, totalmente sometida a la autoridad del Sumo Pontífice. Los primeros Patriarcas reconocidos, en el orden histórico, son los de Constantinopla, Alejandría de Egipto, Antioquía y Jerusalén" ${ }^{17}$.

Posteriormente, el Decreto Orientalium Ecclesiarum concretó más el concepto y sus atribuciones, y recalcó que, sin perjuicio del primado del Papa, según la antiquísima tradición de la Iglesia, los Patriarcas orientales han de ser honrados de una manera especial, y debe observarse una precedencia de honor hacia

15 Así se relata en el "Comunicado n. 11", de dicha fecha, difundido por la Oficina de prensa del Concilio. Original en la biblioteca de la UPSA.

16 Un estudio sobre la institución patriarcal y sobre los patriarcados, tanto de las Iglesias orientales católicas como de las separadas puede encontrarse en Ángel Santos, "Organización eclesiástica de las Iglesias orientales”, Revista Española de Derecho Canónico 83 (1973): 321-358.

17 Oficina de prensa del Concilio Vaticano II, "El vocabulario del Concilio Ecuménico Vaticano II", letra P. Documento original en la biblioteca de la UPSA. 
los primeros, si bien todos gozan de igual dignidad patriarcal y presiden su patriarcado como padres y cabezas del mismo ${ }^{18}$.

Para concluir este apartado, puede afirmarse que el Concilio Vaticano II mostró la universalidad de la Iglesia, al unir, bajo la misma fe y fidelidad a la Sede Apostólica, toda la rica diversidad de tradiciones, costumbres, procedencias, idiomas, etc., que forman la Iglesia católica. Al tiempo, tal variedad evidenció que la diversidad justifica que se pueda hablar de la Iglesia latina y de las Iglesias orientales, así como que se dote a estas últimas de un derecho propio. En cambio, no implica de ningún modo la existencia de dos Iglesias, o de Iglesias paralelas, sino que, por el contrario, tales particularidades, que reflejan la tradición apostólica, están llamadas a contribuir singularmente a la unidad de toda la Iglesia y a realizar su misión. Del mismo modo, una legislación adecuada para las Iglesias orientales, lejos de separar, contribuiría a reforzar dicha unidad y dotaría a la Iglesia de una gran riqueza canónica.

\section{UN CÓDIGO PARA CADA ‘PULMÓN’ DE LA IGLESIA}

4. 1. La cuestión de uno o dos Códigos en la Iglesia durante el proceso codificador del derecho oriental

Como se ha dicho, los ritos orientales católicos tienen su origen en una de las cinco grandes tradiciones orientales ${ }^{19}$. Estas antiguas y venerables tradiciones son consideradas las madres de la fe, por cuanto cada una de ellas, como originarias, dieron lugar posteriormente a otras expresiones eclesiales a modo de hijas ${ }^{20}$. Ello significa que todos los ritos orientales, aún diferentes entre sí, derivan de alguna de estas cinco familias rituales y son, por tanto, manifestaciones de alguna de ellas.

Las connaturales y legítimas diferencias entre ellos, así como especialmente con la Iglesia latina, justificaron que los dos Concilios ecuménicos vaticanos sentenciasen que habían de tener su reflejo en el Derecho canónico. El Vaticano II declaró solemnemente que tanto las Iglesias de Oriente como las de Occidente gozan del derecho y deber de regirse según sus respectivas disciplinas

18 Concilio Vaticano II, OE 7-9. Tal concepto y consideración fue recogido en el Título IV del CCEO, especialmente en los cc. 55, 56, 58 y 59.

19 El c. 28 § 2 del CCEO dispone "Los ritos de que trata el Código son, a menos que conste otra cosa, los que traen su origen de las tradiciones alejandrina, antioquena, armenia, caldea y constantinopolitana".

20 Concilio Vaticano II, "Constitución dogmática sobre la Iglesia Lumen Gentium" (21 de noviembre de 1964), 23 d. En adelante se citará en forma breve como Concilio Vaticano II, LG. 
peculiares $^{21}$, de lo cual se deriva inexcusablemente la conveniencia de la existencia de dos Códigos, diferentes y completos, para los respectivos fieles.

Tal convicción venía de muchos años atrás, pues ya Pío Nono, el 19 de marzo de 1865, había constituido una Comisión preparatoria del Concilio Vaticano I para las Misiones y las Iglesias de rito oriental, que desarrolló el primer intento de una compilación oficial del derecho de las Iglesias orientales católicas, es decir, de un completo Código de derecho canónico, general y acorde a los tiempos ${ }^{22}$. La necesidad de un derecho codificado propio para las Iglesias orientales se hizo sentir con fuerza, por tanto, ya desde los momentos de la preparación del Vaticano I, durante el cual se alzaron "graves voces favorables a la tutela de la disciplina de los orientales" ${ }^{23}$ y se pidió un derecho canónico congruente con los cánones antiguos y los postulados del Concilio. Como es sabido, este Concilio fue interrumpido el 20 de octubre de 1970 y aplazado sine die a causa de la ocupación de Roma por los piamonteses, pero el estudio de la disciplina para las Iglesias orientales no fue detenida en los lustros siguientes. Por el contrario, León XIII quiso que el trabajo fuera continuado por las mismas Iglesias concernidas, y con tal fin promovió una serie de Sínodos de las mismas, en los que fueron revisados casi íntegramente los principales capítulos de la disciplina canónica de cada una de ellas.

En 1917 Benedicto XV promulgó el Código de Derecho Canónico para la Iglesia latina, pero también erigió la Congregación para la Iglesia oriental, atribuyendo a la misma las competencias que las otras Congregaciones romanas tenían respecto a la latina. Al tiempo, creó en Roma el Instituto Pontificio de estudios orientales, en el cual se enseñaría e investigaría el derecho canónico concerniente a los cristianos de oriente.

En 1929, una vez analizadas las opiniones de los cardenales miembros de la Congregación para la Iglesia oriental, Pío XI constituía la primera Comisión cardenalicia para los estudios preparatorios de la codificación oriental, con la misión de recoger todas las fuentes del derecho común a todas las Iglesias orientales, así como las propias de cada una de ellas, y codificarlas. Pío XI se había manifestado ya convencido de la necesidad de tal codificación, calificándola como uno de los asuntos más urgentes y afirmando que él mismo presidiría tal tarea ${ }^{24}$.

21 Concilio Vaticano II, OE 5.

22 Pablo Gefaell, "Il diritto canonico orientale nei lavori del Concilio Vaticano I. I voti dei consultori della Commissione preparatoria per le Missioni e le Chiese orientali”, Ius Ecclesiae 18 (2006): 29-30; 49.

23 Prefacio al CCEO, XVIII. Texto que precede en las ediciones del CCEO a la Constitución Apostólica Sacri canones y a los cánones. Cf. $3^{\text {a }}$ ed. bilingüe comentada. Madrid: BAC 2020.

24 Prefacio al CCEO, XX. 
Después de 6 años de arduo trabajo por parte de dicha Comisión, a la que asistían dos Colegios de peritos, la Congregación para la Iglesia oriental publicaba en trece volúmenes las fuentes antiguas y recientes de la disciplina canónica. Como un segundo y definitivo paso, en 1935 Pío XI constituyó una nueva Comisión para redactar el Código oriental ${ }^{25}$. Los trabajos se desarrollaron con este objetivo, de modo que en 1948 Pío XII pudo finalmente dar su aprobación a un Codex Iuris Canonici Orientalis completo, formado por 2666 cánones. Sin embargo, el Papa decidió en ese momento no promulgar tal cuerpo legislativo como un Código, sino hacerlo por partes, según las diversas materias y de modo sucesivo. De ahí que aquellos cánones fueran publicados a lo largo de los años siguientes agrupados según su temática.

El primero en publicarse, el 22 de febrero de 1949, fue el relativo a la disciplina del matrimonio ${ }^{26}$, por la imperiosa necesidad de dotar de una normativa clara y escrita a todos los católicos orientales, tanto a los que vivían en Medio Oriente como a los dispersos en territorios occidentales. A este siguió, por los mismos motivos anteriores, el correspondiente a los juicios, es decir, a la disciplina procesal, publicado el 6 de enero de $1950^{27}$. Seguiría el 9 de febrero de 1952 la disciplina sobre los religiosos, los bienes temporales y el significado de las palabras (la terminología) ${ }^{28}$, y finalmente, el 2 de junio de 1957, se publicaría la parte sobre los ritos orientales y sobre las personas ${ }^{29}$.

A la muerte de Pío XII quedaban aún sin promulgar 1095 cánones, que nunca llegaron a ver la luz dado que Juan XXIII anunció en 1959 la celebración de un nuevo Concilio ecuménico, llamado a renovar la vida de la Iglesia, y como consecuencia, la actualización del CIC y la promulgación de "un nuevo Código del mismo tipo para la Iglesia de rito Oriental" ${ }^{30}$.

Si bien es cierto que los trabajos de redacción para este Código quedarían parados a la espera del resultado del nuevo marco doctrinal y normativo que estableciera el Vaticano II, no por ello la Comisión cesó completamente su actividad, sino que recondujo sus funciones a una tarea interpretadora del derecho

25 Sobre esta cuestión, Marco Brogi, "Codificazione del Diritto Comune delle Chiese Orientali Cattoliche”, Revista Española de Derecho Canónico 124 (1988): 11-13.

26 Pío XII, "Motu proprio Crebrae Allatae”.

27 Pío XII, "Motu proprio Sollicitudinem Nostram"

28 Pío XII, "Motu proprio Postquam Apostolicis Litteris".

29 Pío XII, "Motu proprio Cleri Sanctitati".

30 Valentín Gómez-Iglesias, "La Pontificia Commissio Codici Iuris Canonici Recognoscendo en los años del Concilio Ecuménico Vaticano II: el plan de revisión de las leyes de la Iglesia", Ius Canonicum 83 (2002): 111. 
ya promulgado, y prosiguió con la edición de las fuentes canónicas orientales que había encargado Pío XI a la primigenia Comisión en 1929.

Entre el fin de la primera etapa conciliar y el inicio de la segunda, concretamente el 28 de marzo de 1963, Juan XIII crea la Comisión para la revisión del Código de Derecho Canónico de 1917, la cual, ampliada por Pablo VI y asistida por setenta consultores, realiza una serie de trabajos preparatorios que, a la espera del fin del Concilio, faciliten en su día la redacción del nuevo Código de la Iglesia latina. Entre tales cuestiones preparatorias estuvo nuevamente el debate sobre la utilidad o conveniencia de confeccionar un único Código para toda la Iglesia, o bien, mantener el CIC para la Iglesia latina y avanzar en el Código para las Iglesias orientales ${ }^{31}$.

El asunto quedó zanjado finalmente a favor de la dualidad por amplia mayoría de la Comisión. Entre los razonamientos más representativos, vale la pena resaltar los del cardenal arzobispo de Munich, pues resumen perfectamente el fondo de la cuestión:

"La disciplina vigente en la Iglesia latina hasta tal punto difiere de la disciplina de las Iglesias orientales — que a su vez discrepan tanto entre ellas - que no es posible mandar a ejecución la idea de hacer un código para toda la Iglesia (...); las publicaciones de derecho oriental hechas durante el pontificado de Pío XII, no han sido recibidas en algunas Iglesias orientales porque están exageradamente repletas de espíritu latino (...); absténgase el legislador de emanar en vano un Código para toda la Iglesia"32.

Otros argumentos que apoyaban tal moción, que en el fondo lo que hacía era denunciar el peligro de latinización del derecho oriental, incidían en huir de la uniformidad en materia disciplinar, pues esta había sido rechazada siempre, tanto por los Jerarcas orientales como por los Pontífices. Por otra parte, instaban a ser consecuentes con el aprecio, ratificado por el Concilio Vaticano II, que la praxis de la Sede Apostólica mostraba a las tradiciones orientales, como parte inseparable de la tradición de la Iglesia. Además, advertían que un Código único podría representar un impedimento para el avance en el diálogo ecuménico ${ }^{33}$.

31 Para el detalle sobre los trabajos de la Comisión para la revisión del CIC durante la etapa Conciliar (1963-1965), en relación con la cuestión de los dos Códigos véase Gómez-Iglesias, "La Pontificia Commissio Codici Iuris Canonici Recognoscendo...", 116-128.

32 Texto citado por Gómez-Iglesias, "La Pontificia Commissio Codici Iuris Canonici Recognoscendo...", 115.

33 Gómez-Iglesias, "La Pontificia Commissio Codici Iuris Canonici Recognoscendo...”, 120. 
Una vez que parecía no ponerse ya en duda la necesidad de una dualidad legislativa, se planteó una segunda cuestión. Se trataba de si sería necesario elaborar un Código fundamental o constitucional para toda la Iglesia, común a latinos y orientales, como precedente a ambos Códigos ${ }^{34}$.

Finalmente, se formuló un tercer interrogante fundado en las notables diferencias disciplinares que se daban entre las mismas Iglesias orientales ¿será posible un único Código para todas ellas o serán necesarios varios, adecuados a los diversos ritos?. La Comisión concluyó que sí era factible reunir en un mismo Código las normas y costumbres verdaderamente comunes a todas las Iglesias orientales, y dejar que la diversidad sea normativizada para cada una de ellas a través de los legisladores particulares ${ }^{35}$.

Después de la celebración del Concilio Vaticano II, el papa Pablo VI constituye una nueva Comisión (1972), que será la que elabore y entregue a Juan Pablo II, en enero de 1989, la propuesta definitiva del Codex Canonum Ecclesiarum Orientalium, cuyo texto sería promulgado el 18 de octubre de 1990, y presentado, por el mismo Pontífice, a la asamblea plenaria del Sínodo de los Obispos reunida en Roma el 25 de octubre del mismo mes y año.

\section{2. El CCEO como derecho común y su relación con el CIC}

E1 CCEO establece un derecho común para todas las Iglesias orientales católicas, pero este se ciñe, por respeto a las legítimas diferencias, a las leyes que el legislador universal ha considerado estrictamente necesarias para el bien general de todas ellas. Por tanto, siguiendo del principio de subsidiariedad, que sirvió de guía para su redacción, el Código remite al derecho particular de cada Iglesia en todo lo demás, de modo que cada legislador podrá emanar normas específicas congruentes con las tradiciones propias del rito de la Iglesia que preside $^{36}$.

34 Pablo VI acogería tal idea, y ordenó iniciar los trabajos de tal Código fundamental, conocido como LEF, que se desarrollaron entre 1965 y 1980 y dieron lugar a un texto que, si bien no fue nunca promulgado, fue importante para la redacción de los dos Códigos. A tal cuestión nos referiremos más adelante. Sobre la discusión de este asunto en la Comisión para la revisión del CIC de 1917 cf. Gómez-Iglesias, "La Pontificia Commissio Codici Iuris Canonici Recognoscendo...", 131-132.

35 Gómez-Iglesias, “La Pontificia Commissio Codici Iuris Canonici Recognoscendo...., 123-124.

36 Pablo Gefaell realizó un exhaustivo estudio, con motivo del décimo aniversario de la promulgación del CCEO, sobre diversas cuestiones relativas a la relación de los Códigos (sus consecuencias técnico-jurídicas, la conjugación de la unidad del Corpus con la duplicidad de Códigos, etc.). Pablo Gefaell, "Relaciones entre los dos Códigos del único Corpus iuris canonici", Ius canonicum 78 (1999): 605-626. 
Tanto por las mencionadas diferencias entre la Iglesia latina y las Iglesias orientales, como porque el CCEO es un cuerpo legislativo más reciente que el CIC, formalmente tienen estilos diferentes. No coinciden ni en la extensión global, ni en el modo de ordenar y distribuir las materias, ni siguen un mismo modo de redacción. Junto a las lógicas coincidencias derivadas de lo que necesariamente ha de ser común en la Iglesia católica, existen discrepancias más o menos importantes en función de la regulación concreta de que se trate, las cuales se acentúan lógicamente donde se establezca una normativa relativa a instituciones características o propias de las Iglesias orientales que, en algunos casos, ni siquiera existen en la latina, o viceversa ${ }^{37}$.

En consecuencia, la concordancia entre ambos Códigos no debe confundirse con la uniformidad de las dos legislaciones. Los respectivos cánones 1 dejan claro su ámbito de aplicación. Según el del CIC, este es "sólo para la Iglesia latina", mientras que los cánones del CCEO son "para todas y solas las Iglesias orientales". Ello no impide, sin embargo, esa necesaria comunicación o interconexión en lo que resulte necesario, como así se desprende del mismo c. 1 del CCEO, que añade "a no ser que, en lo referente a las relaciones con la Iglesia latina, se establezca expresamente otra cosa". Así, por ejemplo, esta exclusión respectiva de la otra legislación no afectaría a las normas del CCEO que disciplinan las relaciones entre las diversas Iglesias sui iuris, pues estas pueden resultar también aplicables a la Iglesia latina, a la que, como se dirá más adelante, podemos considerar equivalente, a estos efectos, a ellas, y de hecho viene mencionada explícitamente en diversos cánones ${ }^{38}$.

En cualquier caso, nunca debe confundirse la protección del patrimonio específicamente oriental con el inmovilismo o la prohibición de cualquier novedad. La Iglesia necesita constantemente leer los signos de los tiempos y saber adaptarse a las condiciones de vida de cada época, para vivir plenamente en ella, sin cambiar lo que eclesialmente es inmutable y coherente con sus tradiciones, pero modificando lo contingente para la necesaria armonía de las leyes eclesiales, siempre al servicio de la pastoral de la Iglesia.

Por ello, y a modo de conclusión, podríamos decir que ambos Códigos coinciden en lo sustancial, pero muestran importantes diferencias derivadas de las diversas tradiciones que perviven en el oriente católico, las cuales implican, entre otras, una organización jerárquica peculiar diversa de la latina. El CIC y el

37 Un comentario de los cánones del CCEO, incidiendo en sus diferencias con el CIC, se contiene en la edición comentada a cargo de los profesores de Salamanca, $3^{\mathrm{a}}$ ed. (Madrid: BAC, 2021).

38 Cf. cc. $37,41,207,322 \S 1$ 1, 432, 696, 830 § 1,916 § 5 y 1465 CCEO. 
CCEO no son, por tanto, legislaciones complementarias, pero tampoco contrarias, sino dos sistemas normativos superiores con ámbitos diversos que forman parte de un mismo ordenamiento jurídico de la Iglesia católica universal, que encuentra su unidad en la fe bajo la potestad suprema del Romano Pontífice.

\section{LA REFORMA DEL CIC PARA LA CONCORDIA CON EL CCEO}

\section{DE CONCORDIA INTER CODICES: NECESIDAD Y CLAVES DE LA REFORMA}

Ya durante el Concilio Vaticano II se hablaba de la creciente movilidad de los ciudadanos por todo el mundo por razón de trabajo, pobreza, supervivencia, turismo, etc., todo lo cual incidía en la pastoral de la Iglesia, que debía afrontar lo que dicha movilidad conllevaba y buscar nuevos modos de llegar y atender espiritualmente a personas de diversas procedencias y costumbres.

La realidad de la Iglesia universal, como la misma sociedad humana, ha cambiado mucho más aún desde entonces, y uno de tales cambios viene determinado por la presencia de un número cada vez más significativo y estable de católicos orientales en territorios donde se observa el rito latino. De ahí la oportunidad y necesidad de las iniciativas pastorales que el Papa Francisco ha tomado recientemente, como por ejemplo la creación en abril de 2016 de un nuevo Ordinariato para los fieles orientales residentes en España, encomendado al Cardenal Arzobispo de Madrid ${ }^{39}$, y la reforma del CIC a la que nos referiremos a continuación.

La doctrina canónica venía señalando en los últimos años algunas discrepancias entre las dos codificaciones que provocaban dificultades en la atención pastoral. Consciente de ello, el Santo Padre mandó constituir en el Pontificio Consejo para los textos legislativos una comisión de expertos en derecho canónico oriental y latino, que elaboró un borrador que fue enviado a una treintena de consultores y expertos de todo el mundo, así como a las autoridades de los diversos Ordinariatos latinos para los orientales. Examinadas minuciosamente las observaciones recibidas, el Papa Francisco aprobó el mencionado motu

39 Sobre tal Ordinariato cf. Miguel Campo, "Nobilis Hispaniae Nato. El Ordinariato para los fieles de ritos orientales residentes en España. Presentación y Comentario”, Estudios Eclesiásticos 91 (2016): 889912.

También Astrid Kaptijn, “Ordinariato Apostólico para la atención de los orientales en España”, Ius Canonicum 56 (2016): 771-781.

Y en general, sobre otros Ordinariatos véase Eduardo Baura, "Las circunscripciones eclesiásticas personales. El caso de los Ordinariatos personales para fieles provenientes del anglicanismo", Ius Canonicum 50 (2010): 165-200. 
proprio De concordia inter Codices ${ }^{40}$, con el objetivo general de contribuir a la concordancia de determinados conceptos y normas, y procurar una mayor eficacia y seguridad en la práctica pastoral.

De concordia inter Codices obedece al deseo constante de la autoridad suprema de la Iglesia de proteger y procurar el mantenimiento de las Iglesias orientales, así como al compromiso de hacer posible que los fieles de estas Iglesias puedan hacer efectivo su derecho, que además para ellos es una obligación jurídica, de observar su rito en todas partes ${ }^{41}$. Ello implica, por parte de la jerarquía de la Iglesia latina, un esfuerzo para que los fieles orientales que llegan a territorios tradicionalmente latinos sean acogidos y respetados en su identidad oriental, de forma que puedan vivir la fe según su propio rito, lo cual, al tiempo, permite que no se pierda la mencionada riqueza que portan sus venerables tradiciones eclesiales. En este punto es singularmente importante concienciar a las autoridades eclesiásticas latinas de que tienen tal deber de hacer posible que los católicos orientales puedan cumplir la obligación de observar su rito, poniendo los medios necesarios para ello. Este objetivo está plenamente relacionado con el general de custodia de los ritos orientales, tal y como quiere la Iglesia, puesto que, en la línea de lo que se acaba de apuntar, sólo si se facilita su observancia en la dispersión, podrá conseguirse su conservación ${ }^{42}$.

No es difícil adivinar que la tarea de armonizar la convivencia en el mismo territorio de fieles latinos en mayoría, con fieles orientales en minoría, tiene su complejidad, y requiere un justo equilibrio entre los derechos de unos y otros, de forma que se promueva la colaboración y se eviten interferencias y conflictos.

40 Francisco, "Carta Apostólica dada en forma de motu proprio De concordia inter códices" (31 de mayo de 2016). Fue publicada en el Diario L'Osservatore romano el 16 de septiembre de 2016, páginas 4-5, y la entrada en vigor se produciría el 16 de diciembre de 2016.

41 Recoge tal derecho-deber, el c. $40 § 3$ del CCEO: "los fieles cristianos fomenten todos el conocimiento y estima del propio rito, y están obligados a observarlo en todas partes".

En paralelo, el c. 214 del CIC contempla este aspecto solo como derecho de los fieles de rito latino (no como deber): "Los fieles tienen derecho a tributar culto a Dios según las normas del propio rito aprobado por los legítimos Pastores de la Iglesia, y a practicar su propia forma de vida espiritual, siempre que sea conforme con la doctrina de la Iglesia".

De modo coherente con tal derecho-deber de todos los católicos orientales, el mismo CCEO prohíbe, con carácter general, modificar sus tradiciones: c. 40 1: "Los jerarcas cuiden todos diligentemente la custodia y observancia cuidadosa del propio rito, y no admitan en él cambios, a no ser por razón de su progreso orgánico".

Tal indicación tiene su fuente próxima en el Decreto del Concilio Vaticano II OE 6: "Sepan y tengan por seguro todos los orientales, que pueden y deben conservar siempre sus legítimos ritos litúrgicos y su disciplina, y que no deben introducir cambios sino por razón de su propio y orgánico progreso".

42 Un interesante estudio sobre la normativa oriental y latina referente a los orientales que viven en territorio latino puede verse en Grzegorz Wojciechowski, "La tutela sobre los católicos orientales en los territorios de la Iglesia latina", Review of Comparative Law 26-27 (2016) 107-121. 
No puede olvidarse, además, que entre los propios orientales las diferencias son significativas, y que cada uno de ellos mantiene, esté donde esté, la adscripción a su propia Iglesia sui iuris y la obligación de observancia de su rito ${ }^{43}$.

El motu proprio reforma once cánones, de los cuales los 111 y 112, contenidos en las Normas generales del CIC, evidencian claramente que uno de los objetivos para alcanzar dicha concordia es la unificación conceptual, en concreto, en el modo de designar a las Iglesias orientales.

\section{LA REFORMA CONCEPTUAL: EL RITO Y LA IGLESIA SUI IURIS}

\subsection{Evolución del concepto para designar a las Iglesias orientales}

Comenzaremos haciendo referencia a las expresiones que encontramos en los principales documentos de Concilio Vaticano II. Posteriormente haremos alusión a la discusión sobre los términos en el proceso de codificación del CCEO.

El número 2 del Decreto Orientalium Eclesiarum se refiere a las comunidades orientales católicas como "Iglesias particulares o ritos".

Por su parte, la Constitución dogmática sobre la Iglesia Lumen Gentium afirma, en referencia a las mismas, por un lado, que en el seno de la comunidad eclesiástica universal hay legítimamente "Iglesias particulares, que gozan de tradiciones propias" 44 . Y por otro, más adelante, menciona a las mimas como "grupos estables" o "Iglesias locales" orgánicamente unidos:

"La divina Providencia ha hecho que varias Iglesias fundadas en diversas regiones por los Apóstoles y sus sucesores, al correr de los tiempos, se hayan reunido en numerosos grupos estables, orgánicamente unidos, los cuales, quedando a salvo la unidad de la fe y la única constitución divina de la Iglesia universal, tienen una disciplina propia, unos ritos litúrgicos y un patrimonio teológico y espiritual propios". 45

El primer término, "Iglesia particular", utilizado por Lumen gentium para referirse a las Iglesias orientales (aunque le añade la coletilla "que gozan de tradiciones propias"), es también el vocablo con el que designa posteriormente

43 Cf. cc. 383 § 2; 476 y 518 del CIC; y cc. 192 § 1 y 193 § 1 del CCEO. La fuente de estos cánones es el Decreto del Concilio Vaticano II "Christus Dominus, sobre el ministerio pastoral de los obispos" (28 de octubre de 1965), 23, 3. En adelante se citará como Concilio Vaticano II, CD.

44 Concilio Vaticano II, LG 13.

45 Concilio Vaticano II, LG 23 (último párrafo). 
a la porción de Pueblo de Dios encomendada al Obispo, esto es, la Diócesis ${ }^{46}$. Es evidente, por tanto, que con la misma expresión se designan dos realidades eclesiológicas diferentes, esto es, por un lado las Iglesias orientales con tradiciones propias (agrupación de Iglesias locales unidas orgánicamente) y, por otro, la Diócesis.

La segunda referencia ("grupos estables" o agrupaciones de Iglesias locales de una misma tradición en torno a una Jerarquía común -Patriarca, Arzobispo mayor, Metropolita, etc.-) sería más acorde con la verdadera configuración eclesiológica y jurídica de las Iglesias orientales, pero debe ser concretado en un vocablo acertado.

Recapitulando, ni el término "Iglesia particular" de Lumen gentium, ni el de "ritos", utilizado por Orientalium Eclesiarum, eran adecuados para describir la verdadera naturaleza y singularidad de las Iglesias orientales. De hecho, "Iglesia particular" quedó como definición de Diócesis (según la acepción dada por Lumen gentium 23 y 27) y se incluyó en el Decreto Christus Dominus:

"La diócesis es una parte del Pueblo de Dios que se confía a un obispo para que la apaciente con la colaboración de su presbiterio. Así unida a su pastor, que la reúne en el Espíritu Santo por medio del Evangelio y la Eucaristía, constituye una Iglesia particular". 47

De aquí pasó a los esquemas de elaboración del CIC y quedó incorporado al mismo; e igualmente sucederá posteriormente en el CCEO con su equivalente, la Eparquía $a^{48}$. En cuanto al segundo concepto, designar a las Iglesias orientales como "ritos" no era tampoco hacerlo con propiedad. El mismo Concilio definirá el "rito" como el conjunto de la disciplina eclesiástica, la liturgia y el patrimonio teológico y espiritual de cada Iglesia ${ }^{49}$, y así se recogerá en el c. $28 \S 1$ del CCEO.

46 Concilio Vaticano II, LG 23 (segundo párrafo): "Cada uno de los Obispos que es puesto al frente de una Iglesia particular, ejerce su poder pastoral sobre la porción del Pueblo de Dios a él encomendada, no sobre las otras Iglesias ni sobre la Iglesia universal". Cf. también el n. 28.

47 Concilio Vaticano II, CD 11.

48 C. 368 CIC: "Iglesias particulares, en las cuales y desde las cuales existe la Iglesia católica una y única, son principalmente las diócesis a las que, si no se establece otra cosa, se asimilan la prelatura territorial y la abadía territorial, el vicariato apostólico y la prefectura apostólica así como la administración apostólica erigida de manera estable".

El C. $177 \S 1$ del CCEO define igualmente la Eparquía como Iglesia particular: "La eparquía es una porción del pueblo de Dios cuyo cuidado se encomienda al Obispo con la cooperación del presbiterio, de manera que, unida a su pastor y congregada por él en el Espíritu Santo mediante el Evangelio y la Eucaristía, constituya una Iglesia particular, en la cual verdaderamente está presente y actúa la Iglesia de Cristo una, santa, católica y apostólica".

49 Concilio Vaticano II, OE 3. 
No cabe, por tanto, confundir el rito que observa una determinada Iglesia con ella misma.

Estaba pendiente, por tanto, encontrar un concepto que no diera lugar a equívocos y que definiera adecuadamente la singularidad de tales Iglesias, así como su posición jurídica en relación a otras y en la Iglesia universal. La Pontificia Comisión para la codificación oriental, constituida de nuevo por Pablo VI en 1972 después del paréntesis del Concilio Vaticano II, discutió muy ampliamente las citadas nociones de "Iglesia particular" y de "rito", con el fin de determinar el exacto significado de tales conceptos y acordar un término nuevo, que designase a las Iglesias católicas orientales de acuerdo a su especificidad.

Paralelamente, durante los trabajos para la elaboración de una posible Lex Ecclesiae Fundamentalis (LEF), que se extendieron entre 1965 y 1980 al mismo tiempo que los de revisión del CIC de 1917 y del derecho oriental, Pablo VI determinó que se formase un grupo especial mixto (así llamado por estar formado por miembros de las dos Comisiones Pontificias codificadoras), para revisar el último anteproyecto presentado. Este grupo elaboraría entre 1974 y 1976 un nuevo esquema de LEF que sería posteriormente discutido y perfeccionado para, finalmente, presentarlo al Papa en $1980^{50}$. La LEF no sería nunca promulgada, pero sus trabajos, como dijo Juan Pablo II, no fueron en vano ${ }^{51}$. Efectivamente, a ambos Códigos pasaron muchos de los contenidos de la LEF.

Tal grupo mixto trató, entre otros, el tema de la posible introducción en la LEF de algunos cánones sobre los Patriarcas y Arzobispos mayores ${ }^{52}$, y discutió ampliamente la cuestión conceptual que nos ocupa. Después de estudiar el significado de la expresión conciliar "Iglesias particulares o ritos" ${ }^{53}$, llegó al acuerdo de referirse a las Iglesias orientales con un nuevo término: "Ecclesia ritualis sui iuris ${ }^{54}$. Desdoblando el mismo, la referencia al rito tendría el sentido de patrimonio apuntado, que le dio el Concilio ${ }^{55}$, y la locución sui iuris describiría la autonomía de gobierno de tal Iglesia, reconocida por la Santa Sede, siempre salvada la subordinación al Papa.

50 Cf. Valentín Gómez-Iglesias, "El profesor Lombardía y el proyecto de Lex Ecclesiae Fundamentalis", Fidelium iura 7 (1997): 160-167.

51 Gómez-Iglesias, "El profesor Lombardía...", 179.

52 Gómez-Iglesias, "El profesor Lombardía...," 162.

53 Concilio Vaticano II, OE 2.

54 Marco Brogi, "Le Chiese sui iuris nel Codex Canonum Ecclesiarum Orientalium", Revista Española de Derecho Canónico 131 (1991): 525.

55 Concilio Vaticano II, LG 23; Ibidem, OE 2. 
Por su parte, la Pontificia comisión del Código oriental, había tomado ya la decisión (en su plenaria de marzo de 1974) de examinar de nuevo la noción de rito y de acordar un nuevo término para designar las Iglesias particulares del oriente y del occidente ${ }^{56}$. Finalmente la expresión adoptada fue la de "Ecclesia sui iuris ${ }^{157}$, que quedó incluida en la redacción del Título I del esquema de Código Oriental de 1984 para designar a las Iglesias orientales. De esta forma, "Iglesia sui iuris" fue la locución incorporada al texto definitivo del CCEO presentado al Papa en 1989 y promulgado por este en 1990. Hay que tener en cuenta que en 1984 ya se había promulgado el nuevo CIC, por lo que este no incorporó a sus cánones la expresión acordada en el esquema de CCEO. Pero curiosamente tampoco utilizó en todos sus cánones el término sui iuris que había decidido el citado grupo mixto para elaboración de la LEF (Ecclesiae rituali sui iuris). En el original latino de los cc. 111 y 112 del CIC se puede observar como, por dos veces, menciona a la Ecclesiae rituali sin más, cuando lo que verdaderamente da entidad autónoma a la Iglesia no es la calificación ritual sino la condición sui iuris. Para la traducción al español se tomó "Iglesia ritual autónoma"; al italiano dice "Chiesa rituale di diritto proprio".

En realidad, la expresión Ecclesiae rituali sui iuris, aunque contenía aún esa referencia ritual, innecesaria y que daba lugar a confusión, de hecho introducía ya la calificación de la Iglesia como sui iuris, que es el elemento fundamental para definir su autonomía eclesial y, consecuentemente, su derecho a regirse por un derecho propio, tal y como se verá más adelante cuando se hable de su configuración.

En consecuencia, más allá del rito que caracterice a una Iglesia sui iuris, y que varias pueden compartir, lo que la nueva expresión pone de relieve es el elemento canónico del reconocimiento, por parte de la suprema autoridad de la Iglesia, del derecho de la Iglesia sui iuris a regirse por un derecho propio, de tal modo que se puede decir que Iglesia sui iuris significa, canónicamente, Iglesia de derecho propio.

56 Marco Brogi, “Le Chiese sui iuris...”, cit., 525 y 527.

57 La expresión no era completamente nueva. Aunque no hablaba de Iglesia sui iuris sino de ritos sui iuris, aparece ya el elemento canónico del reconocimiento de la Iglesia. Se podía leer en el c. $303 \S 1,1$ del motu proprio sobre los religiosos, bienes temporales y significado de las palabras para las Iglesias Orientales (Postquam Apostolicis Litteris, promulgado por Pío XII en 1952): "ritus orientales de quibus canones decernunt sunt alexandrinus, antiochenus, constantinopolitanus, chaldaeus et armenus, aliique ritus quos uti sui iuris expresse vel tacite agnoscit Ecclesia". 


\subsection{El rito y la Iglesia sui iuris}

El concepto de rito se recoge en el c. $28 \S 1$ del CCEO:

"El rito es el patrimonio litúrgico, teológico, espiritual y disciplinar, distinto de la cultura y de las circunstancias históricas de los pueblos, y que se expresa en el modo de vivir la fe propia de cada Iglesia sui iuris" ${ }^{958}$.

De acuerdo con esta definición, el rito va mucho más allá del conjunto de particularidades litúrgicas, esto es, de la normativa que rige la acción litúrgica del culto divino, con la cual a veces se identifica erróneamente. La liturgia está regulada por el derecho litúrgico propio, recogido en parte en el Código y mayormente en los libros litúrgicos, a los que el CCEO, igual que hace el CIC, remite de modo constante en esta temática. La Congregación para las Iglesias Orientales lo ha especificado afirmando que el patrimonio oriental es más amplio que la sola liturgia, y que no se debe favorecer la tendencia a reducir el patrimonio específico de las Iglesias orientales exclusivamente a su dimensión litúrgica ${ }^{59}$.

El rito comprende, por tanto, el conjunto de todo el bagaje teológico y espiritual propio, además de las características disciplinares distintivas. $\mathrm{Y}$ es en estas últimas, precisamente, donde se encuentran las mayores diferencias entre la Iglesia latina y las Iglesias orientales, e incluso entre ellas mismas.

Por su parte, el c. 27 del CCEO define la Iglesia sui iuris como:

"La agrupación de fieles cristianos junto con la jerarquía, a la cual la autoridad suprema de la Iglesia reconoce expresa o tácitamente como sui iuris".

Como se evidencia, si comparamos las definiciones de los cánones 27 y 28 $\S 1$, no cabe confusión alguna entre el rito propio de una Iglesia sui iuris, y la misma Iglesia sui iuris como tal. De hecho, el c. 27, al definir la Iglesia sui iuris, ni siquiera menciona el rito, dejando su noción para el sucesivo c. 28. El motivo

58 Tal definición tiene su fuente principal en OE del Concilio Vaticano II, y ha sido en adelante utilizado en posteriores documentos doctrinales. Cf. Juan Pablo II, OL 1.

59 Cf. Congregación para las Iglesias orientales, "Instrucción para la aplicación de las prescripciones litúrgicas del CCEO" (6 de enero de 1996), 13. Esta Congregación es un punto fundamental de referencia para estas Iglesias. Se ocupa institucionalmente: de animar a las Iglesias orientales a conservar sus tradiciones y a abrirse a las Iglesias hermanas cristianas aún no en plena comunión con el Romano Pontífice, apoyando el diálogo entre ellas; dar a conocer la comunidad oriental a la comunidad latina, estudiar los problemas de los orientales en territorios latinos y moderar los conflictos de jurisdicción que pudieran surgir entre las respectivas jerarquías.

Sobre la historia, potestad y funciones de esta congregación se puede ver el amplio estudio de Marco Brogi, "L'impegno quotidiano della Congregazione per le Chiese orientali", Revista Española de Derecho Canónico 141 (1996): 681-693. 
de esta clara diferenciación de conceptos obedece a que el rito no es un elemento que por sí solo constituya jurídicamente una Iglesia sui iuris ${ }^{60}$, ni es, en sí mismo, un centro de imputación de derechos y deberes, como sí lo es esta última. De ahí que la reforma introducida por De concordia inter codices modifique los cc. 111 y 112 del CIC, y suprima tres expresiones confusas: "Iglesia ritual autónoma", "Iglesia ritual" e "Iglesia del rito", y las sustituya por el término apropiado: "Iglesia sui iuris"61. En el mismo sentido, la reforma del c. $535 \S 2$ del

60 De hecho, por ejemplo, la Iglesia ambrosiana (Italia) tiene su propio rito, pero no es una Iglesia sui iuris sino que depende de otra Iglesia que sí tiene este carácter.

61 En el siguiente cuadro comparativo se puede ver la modificación de términos y la reforma operada en ambos cánones. A la izquierda, los viejos cánones, en los que se resaltan en negrita los términos sustituidos. A la derecha el nuevo texto, con sus modificaciones y añadidos.

\begin{abstract}
Can. 111
\$1. El hijo cuyos padres pertenecen a la Iglesia latina se incorpora a ella por la recepción del bautismo, o si uno de ellos no pertenece a la Iglesia latina, cuando deciden de común acuerdo que la prole sea bautizada en ella; si falta el acuerdo, se incorpora a la Iglesia del rito al que pertenece el padre.
\end{abstract}

\$2. Cualquier bautizando que haya cumplido catorce años, puede elegir libremente bautizarse en la Iglesia latina o en otra Iglesia ritual autónoma; en este caso, pertenece a la Iglesia que ha elegido.

\section{Can. 112}

\$1. Después de recibido el bautismo, se adscriben a otra Iglesia ritual autónoma:

$1^{\circ}$ quien obtenga una licencia de la Sede Apostólica;

$2^{\circ}$ el cónyuge que, al contraer matrimonio, o durante el mismo, declare que pasa a la Iglesia ritual autónoma a la que pertenece el otro cónyuge; pero, una vez disuelto el matrimonio, puede volver libremente a la Iglesia latina;

$3^{\circ}$ los hijos de aquellos de quienes se trata en los nn. 1 y 2 antes de cumplir catorce años, e igualmente, en el matrimonio mixto, los hijos de la parte católica que haya pasado legítimamente a otra Iglesia ritual; pero, alcanzada esa edad, pueden volver a la Iglesia latina.

$\S 2$. La costumbre, por prolongada que sea, de recibir los sacramentos según el rito de alguna

\section{Can. 111}

\$1. Con la recepción del bautismo queda adscrito a la Iglesia latina el hijo de los progenitores que pertenecen a ella o, si uno de los dos no pertenece a ella, cuando ambos progenitores de común acuerdo hayan elegido que la prole fuera bautizada en la Iglesia latina; si falta el común acuerdo, queda adscrito a la Iglesia sui iuris a la que pertenece el padre.

Nuevo §2. Si solamente uno de los progenitores es católico, queda adscrito a la Iglesia a la que pertenece este progenitor católico.

§ 3. Cualquier bautizando que haya cumplido catorce años de edad puede libremente elegir ser bautizado en la Iglesia latina o en otra Iglesia sui iuris; en este caso, pertenece a la Iglesia que haya elegido.

\section{Can. 112}

\$1. Después de recibido el bautismo, se adscriben a otra Iglesia sui iuris:

$1^{\circ}$ quien obtenga una licencia de la Sede Apostólica;

$2^{\circ}$ el cónyuge que, al contraer matrimonio, o durante el mismo, declare que pasa a la Iglesia sui iuris del otro cónyuge; pero una vez disuelto el matrimonio, puede volver libremente a la Iglesia latina;

$3^{\circ}$ los hijos de aquellos de los que se trata en los nn. 1 y 2 antes de cumplir catorce años de edad y, de igual manera, en el matrimonio mixto, los hijos de la parte católica que haya pasado legítimamente a otra Iglesia sui iuris; no obstante, alcanzada esa edad, ellos mismos pueden volver a la Iglesia latina.

$\S 2$. La costumbre, por prolongada que sea, de recibir los sacramentos según el rito de alguna otra 
CIC sustituye la expresión "anotación del cambio de rito", por la de "cambio de Iglesia sui iuris".

Con la nueva terminología introducida por la reforma, tanto el CCEO como el CIC vienen a distinguir neta y definitivamente tales conceptos, superando la confusión anterior, que el Concilio Vaticano II, como se ha visto antes, no contribuyó a clarificar.

El sujeto de derecho es, por tanto, la Iglesia sui iuris, en tanto que persona jurídica reconocida como tal, no el rito o la tradición de la que trae su origen. No obstante, ello no impide afirmar también que una Iglesia sui iuris no puede entenderse desligada de su propio rito, esto es, del patrimonio litúrgico, teológico, espiritual y disciplinar que expresa su modo peculiar de vivir la fe. La existencia de tal patrimonio propio, que unifica normalmente a varias Iglesias particulares llamadas eparquías en torno a un jerarca, es precisamente el fundamento de la autonomía de cada una de estas Iglesias en el seno de la Iglesia católica universal ${ }^{62}$.

En resumen, no basta para que canónicamente se reconozca la existencia de una Iglesia sui iuris que haya un conjunto de Iglesias particulares eparquiales en comunión que compartan el mismo rito. Es necesario, además, que reciban el reconocimiento, expreso o tácito, de la autoridad suprema de la Iglesia, a quien corresponde atribuirle la condición sui iuris.

\begin{tabular}{|l|l|}
\hline $\begin{array}{l}\text { Iglesia ritual autónoma no lleva consigo la ads- } \\
\text { cripción a dicha Iglesia. }\end{array}$ & $\begin{array}{l}\text { Iglesia sui iuris no comporta la adscripción a di- } \\
\text { cha Iglesia. } \\
\text { Nuevo §3. Todo paso a otra Iglesia sui iuris tiene } \\
\text { valor desde el momento de la declaración hecha } \\
\text { en presencia del Ordinario del lugar de dicha Igle- } \\
\text { sia o del pároco propio o del sacerdote delegado } \\
\text { por uno de ellos y de dos testigos, a no ser que un } \\
\text { rescripto de la Sede Apostólica disponga otra } \\
\text { cosa, y se anotará en el libro de bautismos. }\end{array}$ \\
\hline
\end{tabular}

62 Sobre estos argumentos y cuestión cf. Miguel Campo, "Iglesia sui iuris. Un concepto canónico novedoso", Estudios Eclesiásticos 86 (2011), 678-679; Miguel Campo, “De Concordia inter Codices. Primer comentario a la reforma del CIC para avanzar en la concordancia entre los dos Códigos de la Iglesia católica", Estudios Eclesiásticos 91 (2016), 868. 


\section{LA CONFIGURACIÓN DE LA IGLESIA SUI IURIS}

\section{ELEMENTOS MATERIALES Y FORMALES}

Partiendo de la definición dada por el c. 27 del CCEO, cada una de las Iglesias sui iuris vivirá la fe de modo peculiar según su rito propio, tal y como lo define el c. $28 \S 1$, el cual se encuadrará, según su origen, en alguna de las cinco grandes tradiciones orientales que enumera el c. $28 \S 2$.

Los elementos materiales de la Iglesia sui iuris serán, por tanto, una comunidad estable, una liturgia peculiar, un patrimonio teológico, espiritual y disciplinar particular, y una jerarquía propia. Pero junto a estos, resulta necesario que se dé un elemento formal, cual es el reconocimiento de la autoridad suprema de la Iglesia, que dota canónicamente a cada Iglesia de la condición sui iuris, como se desprende del texto del c. 27. Como ya se ha dicho, tal reconocimiento canónico es el que la dota de autonomía de gobierno, aunque esta sea siempre relativa, es decir, limitada, por una parte, por lo que establezca el derecho común (leyes y costumbres de la Iglesia universal, así como, leyes y costumbres comunes a todas las Iglesias orientales $)^{63} \mathrm{y}$, en cualquier caso, por el poder supremo del Romano Pontífice.

Una Iglesia sui iuris está estructurada, generalmente, por varias Iglesias particulares o eparquías bajo una autoridad jerárquica común: un patriarca, un arzobispo mayor, un metropolita o, si excepcionalmente la Iglesia sui iuris está formada por una única circunscripción, un jerarca ${ }^{64}$. Son cuatro, por tanto, las posibles formas de Iglesia sui iuris: Iglesia patriarcal, Iglesia arzobispal mayor, Iglesia metropolitana y las demás Iglesias sui iuris ${ }^{65}$. Todas ellas entran en la

63 C. $1493 \S 1$ CCEO. El derecho común se diferencia del derecho particular, que se establece por exclusión, es decir, comprende todas las leyes, costumbres, estatutos y demás normas no comunes ni a la Iglesia universal ni a todas las Iglesias orientales ( $\$ 2$ del mismo canon).

64 CC. 55-176 CCEO.

65 Las Iglesias patriarcales son seis: la Iglesia de Alejandría de los Coptos (Egipto); las tres Iglesias de Antioquía (de los Sirios, de los Greco-Melquitas y de los Maronitas), la Iglesia de Babilonia de los Caldeos, y la Iglesia Cilicia de los Armenos. Fuente: Oficina Central de Estadísticas de la Iglesia, Anuario Pontificio (Città del Vaticano: Libreria editrice vaticana, 2021) 3-6.

La regulación de las Iglesias patriarcales se contiene en el Título IV del CCEO (cc. 55-150). El Patriarca, a quien compete la potestad sobre todos los Obispos de la Iglesia que preside, incluidos los Metropolitas, es elegido en el Sínodo de los Obispos de la Iglesia patriarcal y adquiere el oficio una vez haya aceptado y sido entronizado, pero debe pedir cuanto antes al Papa la comunión eclesiástica (cc. 56, 63, 76 y 77 CCEO). El Metropolita preside una provincia eclesiástica, formada por varias Eparquías, dentro de la Iglesia patriarcal (c. 133 CCEO).

Las Iglesias Arzobispales Mayores son cuatro: Kyiv-Halyc de los Ucranianos; Ernakulam-Angamaly de los Siro-Malabares; Trivandrum de los Siro-Malankares, y la Fagaras Alba Julia de los Rumanos (Fuente: Anuario Pontificio, cit., 7-8). Estas Iglesias están asimiladas en gran medida a las patriarcales (cc. 151-154). 
definición del c. 27 CCEO y, por tanto, son Iglesias sui iuris y gozan del derecho a regirse por su propio derecho.

A la vista de tal estructura peculiar, Miguel Campo afirma que "nos encontramos, pues, y este sería el elemento característico y definidor de una Iglesia sui iuris, ante una estructura intermedia entre la Iglesia universal, congregada en torno al Romano Pontífice, y las Iglesias particulares, confiadas al gobierno pastoral de los obispos, constituida por la reunión orgánica de varias Iglesias particulares-eparquías"66.

En función del modo de intervención del Papa en el establecimiento de la Jerarquía que preside una Iglesia sui iuris, se dan distintos grados de autonomía y diversidad estructural en cada uno de los cuatro tipos de Iglesias sui iuris mencionados. Nótese que los grupos de Iglesias sui iuris se clasifican en función de la autoridad jerárquica, no del rito, por lo que, como se ha dicho, no cabe confusión entre ambos conceptos.

La forma más completa y compleja de Iglesia sui iuris es la patriarcal. Su venerable antigüedad, que se retrotrae a los tiempos más remotos de la Iglesia, unida a su reconocimiento desde los primeros concilios ecuménicos, fue reconocida por el Concilio Vaticano II. De ahí la honra especial, a la que hemos aludido anteriormente, que se viene dispensando a los Patriarcas, que preceden en todo el mundo a los Obispos, sea del grado que fueren. A estos les siguen en la precedencia de honor los Arzobispos mayores, a los que se aplica, según las normas del derecho, lo dicho en el CCEO respecto a los Patriarcas ${ }^{67}$.

El Arzobispo mayor es un arzobispo metropolita al frente de toda una Iglesia oriental sui iuris, no reconocida como patriarcal sino como Arzobispal mayor, que tiene en general competencias equivalentes al Patriarca (cc. 151-152); es elegido al igual que este último también en el Sínodo, pero a diferencia de aquel requiere confirmación papal; solo obtenida esta puede ser proclamado y entronizado.

Otras Iglesias sui iuris, no reconocidas ni como patriarcales ni como arzobispales mayores, reciben el título de Iglesias Metropolitanas. Actualmente son cinco: Addis Abeba de Etiopía; Pittsburg de los Rutenos (USA), Preso v para los católicos de rito bizantino (Iglesia Eslovaca); Asmara de Eritrea; y Hajdúdorog para los católicos de rito bizantino (Iglesia Húngara). Fuente: Anuario Pontificio, cit., 9-10. La Iglesia Metropolitana sui iuris es erigida por la Santa Sede dentro de los límites de determinado territorio; depende directamente de la misma, y por ello el Metropolita que la preside es elegido por el Papa de entre una terna, como mínimo, propuesta por el Consejo de jerarcas (cf. cc. 155 y 168 CCEO).

El Jerarca, o en su caso el Exarca al frente de una porción de Pueblo de Dios no erigida en Eparquía (cf. cc. 311-321 CCEO), gobierna las demás Iglesias sui iuris (cf. cc. 174-176 CCEO), que pueden estar formadas por varias Eparquías (por ejemplo, la Iglesia italo-albanesa y la Eslovaca cuentan con dos) o por una única (por ejemplo la Iglesia sui iuris Yugoslava y la Húngara), o también por uno o varios Exarcados apostólicos (por ejemplo, la Iglesia griega, o la búlgara, cuentan con uno, y la Iglesia rusa de rito bizantino con dos).

66 Campo, "Iglesia sui iuris....", 677.

67 CC. 152 y 154 CCEO. 


\section{LA CALIFICACIÓN DE LA IGLESIA LATINA COMO SUI IURIS}

Para concluir este trabajo queremos plantear si el concepto que define a las Iglesias orientales católicas de derecho propio es también adecuado para designar a la Iglesia latina, al menos en un contexto de relación entre ellas.

La premisa básica sería poner de relieve que todas ellas, es decir, las Iglesias orientales sui iuris y la Iglesia latina, son iguales en dignidad y derechos ${ }^{68}$. Partiendo de este dato, se podría considerar a la Iglesia latina una Iglesia sui iuris específicamente sujeta al CIC y gobernada directamente por el Romano Pontífice $^{69}$. Bien es cierto que la Iglesia latina se organiza estructuralmente de modo muy diverso a las Iglesias orientales y, por tanto, no se identifica con ninguna de las cuatro categorías de Iglesias sui iuris que enumera el CCEO. De hecho, si hubiera que asimilarla a alguna de ellas sería a la Iglesia patriarcal, pero realmente en la Iglesia latina tal título es meramente honorífico y no conlleva siquiera potestad de régimen. Cabría concluir, por tanto, que la Iglesia latina, partiendo de aquella paridad sancionada por el Concilio, es una Iglesia con autonomía de gobierno, al igual que las Iglesias orientales sui iuris y respecto de las mismas, pero con diferente configuración y régimen jurídico, no encajando, por tanto, en ninguna de las cuatro clases de Iglesias sui iuris que contempla el CCEO. Por ello no creemos adecuado calificarla, sin más y a todos los efectos, como una Iglesia sui iuris.

Por otra parte, el c. 27 comienza anunciando que la noción de Iglesia sui iuris es relativa al propio ámbito del CCEO: "En este Código se llama Iglesia sui iuris....", por lo que la noción y las consecuencias canónicas de la misma se desenvuelven en su ámbito de aplicación, que es solo el de las Iglesias orientales, según el canon 1, del mismo modo que la Iglesia latina está sometida solo al CIC. Recordemos además, que tal concepto sui iuris fue buscado precisamente para designar a las Iglesias orientales en su especificidad eclesiológica y canónica, no para encontrar un concepto común a todas las Iglesias católicas, incluida por tanto la latina, pues respecto de esta no había ninguna dificultad de conceptualización, como sí sucedía con aquéllas, tal y como se ha puesto de relieve en este trabajo.

68 Concilio Vaticano II, OE 3.

69 Cf. Dimitri Salachas, "Problematiche interrituali nei due codici", Apollinaris 75 (1994): 638-639, quien sostiene que en el CCEO la Iglesia latina es considerada implícitamente como sui iuris.

La misma opinión muestra José San José en el comentario al c. 27 del CCEO, $3^{\mathrm{a}}$ ed. (Madrid: BAC, 2021): 30 .

Cf. también la argumentación de Campo, "La Iglesia sui iuris...”, 683-684. 
Por otra parte, no creemos que el CCEO haya querido, en ningún momento, calificar a la Iglesia latina como Iglesia sui iuris, aparte de porque no le corresponde y no es necesario, porque, como decimos, consideramos que es un término propio de las Iglesias orientales, como lo son otros varios, que resultan específicos de una u otra legislación.

Sin embargo, ello no impide que a efectos relacionales, la Iglesia latina pueda ser considerada equivalente a una Iglesia sui iuris, cuando se traten de cuestiones como la adscripción a una Iglesia por el bautismo, o del tránsito posterior a otra. Por ello no es necesario -aunque solo sea por economía del lenguaje- que se especifique en cada caso, que la adscripción se puede producir a una Iglesia sui iuris oriental o a la Iglesia latina, y que igualmente el paso se puede dar tanto de una Iglesia sui iuris a otra, como de una de estas a la Iglesia latina, o viceversa. Es suficiente, en este contexto, entender que cuando se habla de la adscripción a una Iglesia sui iuris, o del paso de una a otra, la latina está incluida.

Es interesante observar que el modo de expresar la relación entre Iglesias se produce de diversas formas, tanto en el CIC como en el CCEO. Por ejemplo, el c. $111 \S 1$ del CIC establece que si falta el acuerdo de los progenitores (para que el hijo menor de 14 años se adscriba a la Iglesia latina), "se incorpora a la Iglesia sui iuris a la que pertenece el padre" (evidentemente sea esta la latina o alguna de las orientales). Sin embargo, el párrafo tercero del mismo c. 111 dice que el que haya cumplido 14 años "puede elegir libremente bautizarse en la Iglesia latina o en otra Iglesia sui iuris", introduciendo una disyuntiva entre dos realidades, aunque equivalentes a estos efectos.

Algo similar observamos en el CCEO, el cual en algunos casos habla simplemente de adscripción a una Iglesia sui iuris, o del paso de una a otra, sin especificar y, por tanto, incluyendo a la Iglesia latina, mientras que en otros menciona expresamente a la Iglesia latina junto a las Iglesias sui iuris, diciendo que "también" o "incluso la Iglesia latina". Aquí está claro que el CCEO distingue, y lo hace precisamente para que no quepa duda de que lo que establece el canon afecta tanto a unas como a la otra ${ }^{70}$.

En conclusión, no nos parece adecuado calificar a la Iglesia latina como Iglesia sui iuris, pero sí podría considerarse que es una realidad eclesial equivalente, y tratarla como tal, en determinadas materias en las que se establece una relación entre Iglesias.

70 V. gr. cc. 37, 41, 207, 322, 1; 432, 830, 916, 5; 1465. Cánones citados por Dimitri Salachas, "Problematiche interrituali...", cit, 638. 


\section{REFERENCIAS BIBLIOGRÁFICAS}

\section{FUENTES}

Concilio Vaticano II. 1964. "Decreto Orientalium Ecclesiarum”. Consultado el 30 de agosto de 2021, https:/www.vatican.va/archive/hist_councils/ii_vatica n_council/documents/vat-ii_decree_19641121_orientaliumecclesiarum_sp.html

Concilio Vaticano II. 1964. "Constitución dogmática sobre la Iglesia Lumen Gentium". Consultado el 30 de agosto de 2021, https://www.vatican.va/archive/hist_councils/ii_vatican_council/documents/vatii_const_19641121_lumen-gentium_sp.html

Concilio Vaticano II. 1965. "Decreto Christus Dominus". Consultado el 30 de agosto de 2021, https://www.vatican.va/archive/hist_councils/ii_vatican_co uncil/documents/vat-ii_decree_19651028_christus-dominus_sp.h.html

Congregación para las Iglesias oriēntales. 1996. "Instrucción para la aplicación de las prescripciones litúrgicas del CCEO". Consultado el 15 de septiembre de 2021, https:/www.vatican.va/roman_curia/congregations/orientchurch/ Istruzione/pdf/istruzionecongchieseorientali.pdf

Francisco. 2016. "Carta Apostólica dada en forma de motu proprio De concordia inter códices”. Consultado el 1 de septiembre de 2021, https://www.vatican. $\mathrm{va} /$ content/francesco/es/motu_proprio/documents/papa-francesco-motu-proprio_20160531_de-concordia-inter-codices.html

Juan Pab̆lo II. 1990. Codex Canonum Ecclesiarium Orientalium.

Juan Pablo II. 1983. Codex Iuris Canonici.

Juan Pablo II. 1990. "Discorso in occasione della presentazione del Codice dei Canoni delle Chiese Orientali (1990). Consultado el 16 de septiembre de 2021, https:/www.vatican.va/content/john-paul-ii/it/speeches/1990/october/documents/hf_jp-ii_spe_19901025_codice-chiese-orientali.html

Juan Pablo II. 1987. "Carta Encíclica Redemptoris mater”. Consultado el 16 de septiembre de 2021, https://www.vatican.va/content/john-paul-ii/es/encyclica 1s/documents/hf_jp-ii_enc_25031987_redemptoris-mater.html

Juan Pablo II. 1995. "Carta Encíclica Ut uñum sint”. Consultado el 16 de septiembre de 2021, https:/www.vatican.va/content/john-paul-ii/es/encyclic als/documents/hf_jp-ii_enc_25051995_ut-unum-sint.html

Juan Pablo II. 1995. “Carta Apostólica Orientale Lumen”. Consultado el 16 de septiembre de 2021, https://www.vatican.va/content/john-paul-ii/es/apost_let ters/1995/documents/hf_jp-ii_apl_19950502_orientale-lumen.html

Juan Pablo II. 1999. "Exhortación apostólica post sinodal Ecclesia in America". Consultado el 16 de septiembre de 2021, https://www.vatican.va/content/ john-paul-ii/es/apost_exhortations/documents/hf_jp-ii_exh_22011999_ecclesia-in-america.html 
Pío XII. 1950. "Motu proprio Crebrae Allatae". Consultado el 25 de junio de 2021, https://www.vatican.va/content/pius-xii/la/motu_proprio/documents/ hf_p-xii_motu-proprio_19490222_crebrae-allatae.html

Pío XII. 1950. "Motu proprio Sollicitudinem Nostram". Consultado el 25 de junio de 2021, https://www.vatican.va/content/pius-xii/la/motu_proprio/docume nts/hf p-xii_motu-proprio_19500106_sollicitudinem-nostram.html

Pío XII. 1952. "Motu proprio Postquam Apostolicis Litteris". Consultado el 25 de junio de 2021, https://www.vatican.va/content/pius-xii/la/motu proprio/ documents/hf_p-xii_motu-proprio_19520209_postquam-apostolicis.html

Pío XII. 1957. "Motu proprio Cleri Sanctitati", Consultado el 25 de junio de 2021, https://www.vatican.va/content/pius-xii/la/motu_proprio/documents/hf_pxii_motu-proprio_19570602_cleri-sanctitati.html

Pontificio Consejo para la Promoción de la Unidad de los Cristianos. 1993. "Directorio para la aplicación de Principios y Normas sobre el ecumenismo", Consultado el 25 de agosto de 2021, http://www.christianunity. va/content/unitacristiani/it/documenti/direttorio-per-lapplicazione-dei-principi-e-dellenorme-sullecum.html

\section{BIBLIOGRAFÍA SECUNDARIA}

Baura, Eduardo. "Las circunscripciones eclesiásticas personales. El caso de los Ordinariatos personales para fieles provenientes del anglicanismo", Ius $\mathrm{Ca}$ nonicum 50 (2010): 165-200.

Blanco, Pablo, "Las Iglesias orientales católicas y ortodoxas en las enseñanzas del Vaticano II", Scripta Theologica 46 (2014), 357-376.

Brogi, Marco. "Codificazione del Diritto Comune delle Chiese Orientali Cattoliche”, Revista Española de Derecho Canónico 124 (1988): 7-29.

Brogi, Marco. "Le Chiese sui iuris nel Codex Canonum Ecdesiarum Orientalium", Revista Española de Derecho Canónico 131 (1991): 517-544.

Brogi, Marco. "L'impegno quotidiano della Congregazione per le Chiese orientali”, Revista Española de Derecho Canónico 141 (1996): 681-693.

Campo, Miguel. "Nobilis Hispaniae Nato. El Ordinariato para los fieles de ritos orientales residentes en España. Presentación y Comentario", Estudios Eclesiásticos 91 (2016): 889-912.

Campo, Miguel. "Iglesia sui iuris. Un concepto canónico novedoso", Estudios Eclesiásticos 86 (2011), 678-679.

Campo, Miguel. "De Concordia inter Codices. Primer comentario a la reforma del CIC para avanzar en la concordancia entre los dos Códigos de la Iglesia católica", Estudios Eclesiásticos 91 (2016), 868.

De Francisco, Carlos. Las Iglesias orientales católicas. Madrid: San Pablo, 1997. 
Gefaell, Pablo. "Il diritto canonico orientale nei lavori del Concilio Vaticano I. I voti dei consultori della Commissione preparatoria per le Missioni e le Chiese orientali", Ius Ecclesiae 18 (2006):

Gefaell, Pablo. "Relaciones entre los dos Códigos del único Corpus iuris canonici", Ius canonicum 78 (1999): 605-626.

Gefaell, Pablo. "El derecho oriental desde la promulgación del CIC y del CCEO", Ius canonicum 97 (2009): 37-65.

Gómez-Iglesias, Valentín. "La Pontificia Commissio Codici Iuris Canonici Recognoscendo en los años del Concilio Ecuménico Vaticano II: el plan de revisión de las leyes de la Iglesia", Ius Canonicum, 83 (2002): 109-133.

Gómez-Iglesias, Valentín. "El profesor Lombardía y el proyecto de Lex Ecclesiae Fundamentalis" Fidelium iura 7 (1997): 103-182.

Kaptijn, Astrid. "Ordinariato Apostólico para la atención de los orientales en España”, Ius Canonicum 56 (2016): 771-781.

Oficina Central de Estadísticas de la Iglesia. 2021. Anuario Pontificio. Città del Vaticano: Librería editrice vaticana.

Oficina de Prensa del Concilio Ecuménico Vaticano II. "Composición, actividades y características de las Comisiones y Secretariados preparatorios del Concilio Vaticano II". Original Biblioteca UPSA.

Oficina de Prensa del Concilio Ecuménico Vaticano II. "Comunicado n. 11". Ibid.

Oficina de Prensa del Concilio Ecuménico Vaticano II. "El vocabulario del Concilio Ecuménico Vaticano II", letra P. Ibid.

Prefacio (CCEO $3^{\mathrm{a}}$ ed. Madrid: BAC. 2021).

Profesores de Salamanca. Comentario al CCEO, $3^{\mathrm{a}}$ ed., Madrid: BAC 2021.

Salachas, Dimitri. "Problematiche interrituali nei due codici orientale e latino", Apollinaris 75 (1994): 635-690.

Santos, Ángel. “Organización eclesiástica de las Iglesias orientales”, Revista Española de Derecho Canónico 83 (1973): 321-358.

Wojciechowski, Grzegorz. "La tutela sobre los católicos orientales en los territorios de la Iglesia latina", Review of Comparative Law 26-27 (2016): 107-121.

Mirian Cortés Diéguez

Facultad de Derecho Canónico

Universidad Pontificia de Salamanca

C/ Compañía 5. 37002 Salamanca (España) https://orcid.org/0000-0002-0206-6332 